\title{
Restructuring Revisited Part 2: Coordination in Electricity Distribution Systems
}

\author{
Scott P. Burger, ${ }^{\mathrm{a}}$ Jesse D. Jenkins, ${ }^{\mathrm{b}}$ Carlos Batlle, ${ }^{\mathrm{c}}$ and Ignacio J. Pérez-Arriaga ${ }^{\mathrm{d}}$
}

\begin{abstract}
This paper addresses the mechanisms needed to coordinate vertically and horizontally disaggregated actors in electricity distribution systems. The mechanisms designed to coordinate planning, investments, and operations in the electric power sector were designed with minimal participation from either the demand side of the market or distributed energy resources (DERs) connected at distribution voltages. The emergence of DERs is now animating consumers and massively expanding the number of potential investors and participants in the provision of electricity services. We highlight how price signals - the primary mechanism for coordinating investments and operations at the transmission level-do not adequately coordinate investments in and operations of DERs with network infrastructure. We discuss the role of the distribution system operator in creating cost-reflective prices, and argue that the price signals governing transactions at the distribution level must increasingly internalize the cost of network externalities, revealing the marginal cost or benefit of an actor's decisions. Price signals considered include contractual relationships, organized procurement processes, market signals, and regulated retail tariffs. This paper is the second part of a two-part series on competition and coordination in rapidly evolving electricity distribution systems.
\end{abstract}

Keywords: Competition, Coordination, Restructuring, Vertical Integration, Distributed Energy Resources, Distribution, Transmission, System Operation, Networks, Pricing, Tariffs

https://doi.org/10.5547/01956574.40.3.jjen

\section{INTRODUCTION AND FRAMING}

Distributed energy resources (DERs) ${ }^{1}$ and digital technologies dramatically expand the number of potential investors in and operators of power system infrastructure, challenging traditional means of planning and coordinating the construction of generation, storage, and network assets. Distribution-connected resources have historically not participated in traditional means of

1. A DER is any resource capable of providing electricity services that is located in the distribution system. DERs include distribution-connected demand response, generation, energy storage, and energy control devices.

a Corresponding author. Research Associate, Massachusetts Institute of Technology. Mailing address: Scott Burger, MIT Energy Initiative. 77 Massachusetts Avenue Cambridge, MA 02139. E-mail: sburger@mit.edu.

b_Research Associate, Massachusetts Institute of Technology. E-mail: jessedj@mit.edu.

c Research Scholar, Massachusetts Institute of Technology and Electricity Advisor, Florence School of Regulation. E-mail: cbatlle@mit.edu.

d Visiting Professor, Massachusetts Institute of Technology. Professor and Director of the BP Chair on Sustainable Development, Comillas University. Director of Energy Training, Florence School of Regulation. E-mail: ipa@mit. edu.

The Energy Journal, Vol. 40, No. 3. Copyright (C) 2019 by the IAEE. All rights reserved. 
executing least cost, security-constrained dispatch of generation and typically face inefficient retail tariffs as opposed to market-determined prices. Thus, the emergence of DERs is challenging the structures historically used to coordinate investments in power system infrastructure in the medium and long term, and to coordinate supply and demand to ensure reliable operations of power systems in real time.

During the wave of restructuring that swept through the electricity industry in the 1980s, 1990s, and 2000s, regulators established or sanctioned market constructs in order to ensure efficient pricing and the development of an efficient mix of transmission and generation assets in the short and long run (European Commission, 2009; FERC, 1999; P. L. Joskow, 1996). Today, the emergence of DERs is spurring regulators to engage in analogous debates over how to ensure the efficient utilization of and investment in both DERs and the system's conventional suite of network, generation, demand, and storage resources. Existing industry structures need to be revisited once again, to guarantee that they do adequately achieve these goals.

This is the second paper in a two-part series that explores the implications of decentralization and digitization for competition and coordination in electricity distribution systems. Part 1 analyzes the economic characteristics of the distribution-level roles required for efficient planning and operation of the power system and the implications of these characteristics for industry structure, competition, market development, and economic efficiency. Part 2 (this paper) analyzes the pricing mechanisms and institutional arrangements needed to coordinate actions between the distribution network owners and operators, bulk power system stakeholders, DER owners, and electricity consumers.

Efficient coordination of investments and operations of a mix of generation and energy storage devices at various scales, demand-side flexibility, and transmission and distribution network assets holds the potential to reduce overall electricity costs relative to a system with uncoordinated investments (Baldick \& Kahn, 1993; Ignacio J. Pérez-Arriaga et al., 2016). In power systems where actors remain vertically integrated across generation, transmission, distribution, and retail, this coordination requires a set of internal planning and operating decisions and appropriate external price signals, incentives and/or communications with electricity users. In systems with competition in generation and/or retail, this coordination requires multilateral arrangements between monopoly network providers and market actors and, in many cases, market-facilitated price signals and contracts for energy, capacity, and ancillary services. Wholesale market constructs and the planning processes orchestrated (in part) by bulk system balancing authorities (BAs) ${ }^{2}$ provide the frameworks for coordinating investment planning and operation at the bulk system level, but similar arrangements are nascent or non-existent at the distribution level.

Sections 2 and 3 provide a literature review and background on the interplay between industrial structure and coordination of actors. Section 4 begins with a discussion of which actor - the distribution system operator or the bulk system balancing authority — will be responsible for price formation at the distribution level. Section 4 discusses necessary improvements in short term price signals, and Section 5 discusses the role of long-term contracts and forward markets for distribution level services.

2. We refer to the actor responsible for bulk power system balancing and real-time dispatch as the Balancing Authority or BA. The BA can take many forms. In the U.S., vertically integrated utilities, independent system operators (ISOs), and regional transmission operators (RTOs) perform balancing in different geographies. In the European Union, balancing is performed by transmission system operators (TSOs). Where it is important to do so, we distinguish between a vertically integrated utility, an independent RTO or ISO, or a TSO. 
This paper has implications for two questions that are currently being debated by regulators and policy makers globally:

1. What is the role of the distribution system operator (DSO)-independent or otherwise - in future power system operations?

2. What market mechanisms, if any, might be needed under different institutional arrangements to coordinate efficient investment and operational decisions across various actors?

We argue that price signals at the distribution level must be dramatically improved to ensure that network users adopt and operate DERs in a way that maximizes the welfare of the power system as a whole, rather than for any one network user at the expense of others. We argue that no single actor today has visibility into the distribution system and capability to run the systems necessary for efficient price formation. We describe three possible paths forward, and describe the key tradeoffs between these paths. Improving price signals at the distribution level will also require significant improvements in electricity tariff design. Default tariffs must align individual incentives with cost-savings opportunities for the system as a whole. In markets with retail competition, settlement rules for retailers must be updated to ensure that these retailers are financially responsible for the customers they serve and economically incentivized to facilitate efficient consumption, injection, and investment decisions. Finally, new market mechanisms such as auctions for non-wires alternatives may be necessary, as short run prices may not coordinate the efficient level and timing of investment in non-wires alternatives.

\section{LITERATURE REVIEW}

Recent literature on coordination at the distribution level has concentrated on three broad issues:

1) the evolving roles of the DSO in system operations;

2) coordination of the DSO and bulk system balancing authorities (BAs) and power markets;

3) the role of price signals in incentivizing efficient DER investment and operations.

We briefly summarize the literature on each of these three dimensions below.

The evolving roles of the DSO in system operations. The U.S. Department of Energy's DSPx Initiative (2017) defines many of the capabilities and functions of future distribution network, system, and market operators in a descriptive fashion, focusing on the actions required to ensure reliable system operations. Martini et al. (2015) and Kristov et al. (2016) discuss alternative models for assigning distribution level roles to power system actors and advocate for increasing the responsibility of the DSO in power system balancing and real time operations. Similarly, Corneli et al. (2015) offers two descriptive high-level visions of the future of DER integration for distribution utilities, but does not compare the potential efficiency of these visions or the key economic tradeoffs. Bahramirad et al. (2016) describes a vision for a DSO that takes primary responsibility over scheduling resources and demand within its service territory, but do not compare this structure to other potential structures.

DSO-BA coordination. A number of authors have focused on coordinating DSO activities with bulk system balancing authorities. Ruester et al. (2014) highlight the changing nature of the DSO vis-à-vis the bulk system BAs and argue for increased regulatory oversight to ensure that DSOs do not abuse their monopoly positions in aggregation and DER markets. Both Martini et al. 
(2015) and Kristov et al. (2015) largely dismiss the potential for a "total TSO" model, in which the bulk power system balancing authority manages most distribution level operations. California Independent System Operator (CAISO) et al. (2017) provides a near term roadmap for coordination in the California context, focusing on ensuring that distribution network constraints are respected in market and balancing operations. Many other industry reports and academic papers have focused on this issue, primarily outlining different methods for ensuring operational feasibility in the near term (see, for example, (ENTSO-E, 2017)).

The role of price signals. Scholars have analyzed the interaction between price signals and DER adoption for well over a decade. For example, Firestone et al. (2006) highlight the negative impact of fixed-charges in tariffs on fossil-fuel-based DG. In more recent years, a litany of studies have focused on network cost recovery in the face of distributed solar (Borenstein, 2017; Brown \& Sappington, 2017; Darghouth, Barbose, \& Wiser, 2011), the impact of demand charges on storage economics (Hledik \& Greenstein, 2016; Neubauer \& Simpson, 2015), and incentivizing the optimal placement of DERs through tariffs (Ignacio J. Pérez-Arriaga et al., 2016; Sioshansi, 2016). Related to the discussion of DER economics and pricing, interest in distribution-level locational marginal prices (DLMPs) has accelerated in recent years. The literature on DLMPs is vast, but researchers are broadly focusing on methods for creating efficient short run marginal costs accounting for distribution level constraints (M. Caramanis, Ntakou, Hogan, Chakrabortty, \& Schoene, 2016; Papavasiliou, 2017).

We build upon the body of literature by bringing the tariff design debate into the discussion of coordination mechanisms needed for vertically and horizontally disaggregated industries. We also analyze the role of the DSO in system operations in a transaction cost economics lens, providing a new perspective with which to analyze the issue. By translating the foundational theory and modern work in markets and hierarchies to the present situation, this provides a more holistic framework with which to make informed structure decisions.

\section{INDUSTRY STRUCTURE AND COORDINATION}

The power sector was historically dominated by either a regional, vertically integrated monopoly generator or a relatively limited number of power producers investing in large plants. Entry into the generation sector in this paradigm was relatively easy to monitor. Generator operations, entry, or exit that would have notably negative impact on system costs or reliability was easily managed. However, today, there are relatively few barriers preventing consumers or other investors from adopting DERs in most developed power systems. Indeed, many DERs ${ }^{3}$ are consumer products and require no formal interconnection procedure to speak of. Consumers do not need to coordinate with the distribution network owner and operator $(\mathrm{DNO} / \mathrm{SO})$ to install and operate these devices, despite the fact that these devices can have significant impact when considered in aggregate (see, for example, Mathieu et al. (2012)). If properly located and operated, DERs hold the potential to reduce system costs (see, e.g., Cohen et al. (2015)) and emissions (see, e.g. Gilbraith and Powers (2013)). On the other hand, inefficiently located and operated DERs could increase system costs (see, e.g., Schmalensee et al. (2015)) and emissions (see, e.g., Fares and Webber (2017)). Furthermore, DERs that arbitrage flawed tariff designs can threaten the financial viability of the companies that manage our critical electricity infrastructure (Kind, 2013) or result in economic transfers between network users that may be regarded as inequitable (Burger, Schneider, Botterud, \& Pérez-Arriaga, 2019).

3. For example, "smart" appliances. 
Some DER owners are motivated to invest in and operate DERs at least partially by non-economic factors such as peer effects (Bollinger \& Gillingham, 2012) or by private value decisions such as a personal premium placed on environmentally responsible or local generation. However, for the majority of customers and investors, economic incentives significantly influence (if not wholly determine) DER adoption and operation decisions. Price signals are thus one of best means to coordinate DER investment and operation decisions by influencing where and when DERs provide electricity services (Ignacio J. Pérez-Arriaga et al., 2016).

Even in systems in which the DNO/SO is vertically integrated into generation and DER ownership, the DNO/SO must have mechanisms to incentivize efficient DER deployment and coordinate DER and network investment decisions, as the majority of DNO/SOs are mandated to interconnect DERs upon request. ${ }^{4}$ Thus, in all industry structures, the importance of efficient price signals grows as the competitiveness of DERs increases.

We summarize the price signals that influence DER investment and operation decisions in four broad, non-mutually exclusive categories:

1. Energy price signals

2. Network use of system price signals

3. Ancillary services and capacity price signals

4. Subsidies and other policy and regulatory costs

These four categories are not mutually exclusive. For example, wherever nodal prices are implemented, the locational marginal price in a given area reflects the scarcity of network capacity, which can signal the need for network capacity investments. Nonetheless, it is useful to distinguish between these four categories of price signals, as they will be impacted in different ways by different industry organization decisions. There is also an interplay between marginal energy costs and the price signals necessary for recovering network costs. Because differences in marginal energy prices across nodes in the network cannot recover all of the system's network and, in many cases, capacity costs, the remaining "residual" costs must be recovered through tariffs (Rubio-Oderiz \& Pérez-Arriaga, 2000). However, as differences in marginal energy prices rise, the total residual costs that must be recovered fall.

Subsidies and policy and regulatory costs emerge from policy decisions to support certain classes of technologies or customers, or from general taxes. Both decisions to subsidize certain technologies and the methods for recovering the costs of these subsidies can significantly impact industry structure. The motivation for this paper - the rising penetration of DERs - has been spurred in many locations by significant policy support. Thus, these policies have created a need for a reconsideration of industry structure. Similarly, the inefficient allocation of policy and regulatory coststhrough volumetric tariffs, for example - can be highly distortionary and impact the consumption, production, or investment decisions of network users. This in turn affects structure. We discuss this latter issue in Section 6. However, the purpose of this paper is not to discuss the optimal technology support policies, or even the optimal method for recovering policy and regulatory costs. Rather, our focus is on the structures needed to create efficient energy price formation and to enable an efficient mix of generation, network, storage, and demand resources. As a result, we largely avoid discussing policy and regulatory costs.

Today, mechanisms to coordinate DER investments and operations within the power system are limited. For DERs connected "behind the meter" (BTM) at customer sites, the primary

4. Interconnection is typically required as long as these DERs meet local interconnection standards, pay any associated interconnection fees, or pay the cost of network upgrades required to accommodate interconnection. 
coordination signals are retail electricity tariffs, discussed in Section 6. Increasingly, BTM resources are participating in wholesale capacity and energy markets, which represents a promising path towards better integration. DERs connected "in front of the meter" have historically participated more actively in wholesale markets than BTM resources. However, as we discuss in Section 4, these markets do not today account for distribution network conditions - a fact which may become more important as DER penetration rises. Demand response (DR) resources are the sole exception to the rule that DERs have not actively coordinated with other resources in the system. DR investment and operation has long been coordinated with network and generation investments, due primarily to two factors. First, long standing "integrated resources planning" practices required utilities to consider investments in price responsive demand or energy efficiency as alternatives to traditional infrastructure. Second, favorable rules for demand response aggregators has created robust participation of DR in today's wholesale energy and capacity markets.

In Section 4, we discuss the mechanisms needed to coordinate investments and operations in DERs and network assets in the short and long term. We begin with a discussion of the entity responsible for coordinating and dispatching resources on operational timescales in order to ensure reliable power system operations, as these actions determine the prices that coordinate the behavior of other actors. We then discuss the role of short-term price signals in the planning and operation of the distribution system and the power system more broadly. This discussion includes a description of the primary means of communicating these short-term price signals to distribution-connected customers: electricity tariffs. Finally, we conclude with a discussion of the mechanisms and price signals needed to coordinate long term planning and investment.

\section{THE ROLE OF THE DSO VIS-À-VIS BULK SYSTEM BALANCING AUTHORITIES}

Bulk system balancing authorities (BAs) today balance power at the transmission level by:

1. Ensuring the feasibility of power flows scheduled by generators, storage providers, aggregators, and retailers in the weeks- to day-ahead time frames.

2. Issuing security-related dispatch orders to generators in real time to match supply and demand within system operating constraints.

Security-related dispatch orders are the shortest timescale operational decisions in the power system (aside from protection coordination schemes, automatic inertial response, and generator control). The final production and consumption schedules that result from generator and consumer schedules and system operator dispatch decisions result in a set of marginal prices for energy and operating reserves that are related to the marginal cost of the resources providing these services (Hogan, 2013; Schweppe, Caramanis, Tabors, \& Bohn, 1988). Ideally, these prices would align the economic incentives of individual agents with the final scheduled production and consumption decisions cleared by the system operator. Such "equilibrium" prices eliminate the potential for arbitrage, limit the need for carrying reserves, and maximize the system's welfare. In practice, BAs are also therefore generally responsible for generating an incentive-compatible set of final prices for real-time or balancing markets and various reserve products that reflect the marginal cost of matching supply and demand. ${ }^{5}$ Making welfare maximizing security-related dispatch decisions requires

5. The exception is where a vertically integrated utility acts as BA for their own system independent of any organized market. 
the system operator to have a robust knowledge of the network and the constraints and marginal costs of the resources connected to it. However, at present, neither the DSO nor the BA have both visibility into distribution system operations and the capability of computing and communicating optimal distribution-level prices and dispatch orders.

Given their experience in bulk system operations, BAs have many of the capabilities necessary to compute and communicate efficient prices and the associated dispatch orders. However, BAs have little or no visibility into: 1) the network conditions of the distribution networks connected to their system, 2) any DER or aggregator dispatch orders issued by DSOs, or 3) DER operation or consumption decisions made by users connected to the distribution system. ${ }^{6}$ As a result, BAs run the risk of issuing suboptimal dispatch decisions. BAs also run the risk of issuing dispatch orders to DER providers or aggregators that are infeasible due to distribution system constraints or that conflict with dispatch instructions sent by the DSO to consumers, DER providers, or aggregators. Conflicting DSO and bulk system BA orders result from "tier bypassing," wherein an actor in the distribution network makes a physical commitment without incorporating distribution-level network externalities (Taft \& Becker-Dippmann, 2015).

DSOs, on the other hand, have visibility into distribution system operations but, to date, have little to no experience creating economically optimal system operations. In addition, DSOs have little to no visibility into bulk system conditions, and, in many cases, into the investment or operation decisions of DER owners. As a result, DSOs (and, equally often, BAs) lack knowledge of the potential for DERs or demand to take action to support system operations. This has led to a variety of discussions over how to coordinate DSO operations with demand, DER providers, aggregators, and bulk system balancing authorities (Eid, Codani, Perez, Reneses, \& Hakvoort, 2016; ENTSO-E, 2017).

At the highest level, there are three basic models for coordinating the DSO and BA roles and enabling efficient price formation across both transmission and distribution networks, as depicted by Figure 1 below. The numbers in Figure 1 correspond roughly to the order of the flow of information in each model. In each model, the BA and DSO coordinate to some degree to ensure that demand and supply are balanced within transmission and distribution constraints. The goal

\section{Figure 1: Three basic models for coordinating DSOs and bulk system Balancing Authorities}

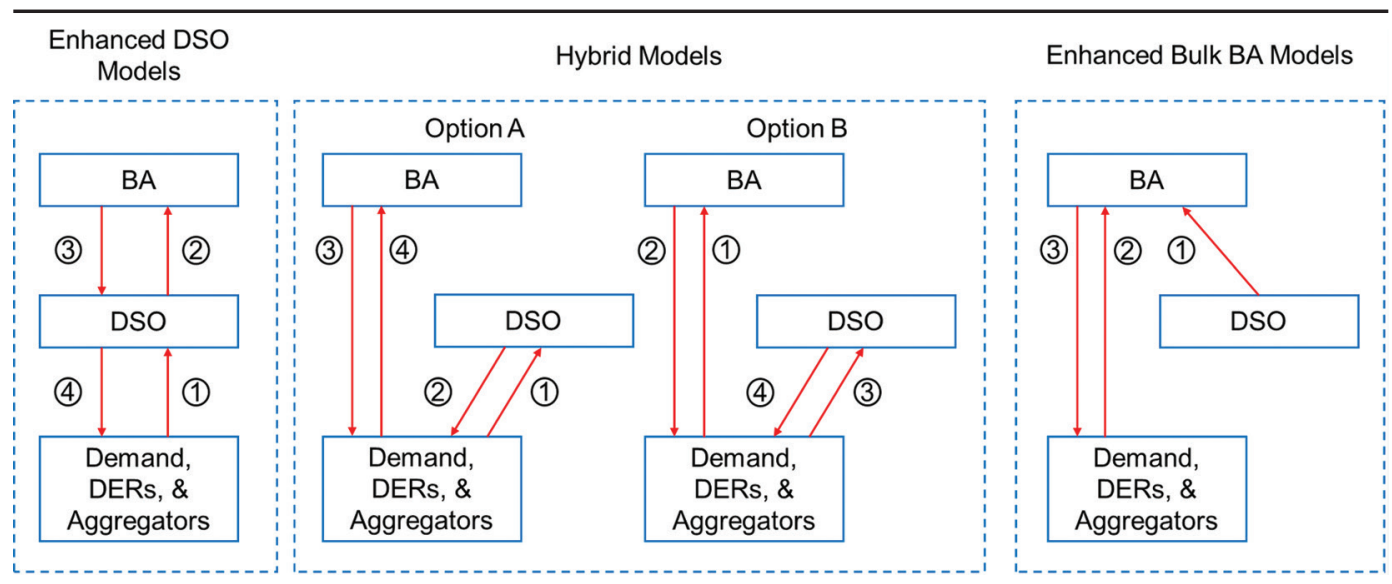

6. This may not be true in cases where the BA is a vertically integrated utility, as, in theory, the vertically integrated utility has visibility over its entire network. Such visibility may not be true in practice given technological shortcomings (for example, limited smart meter deployment or lack of SCADA coverage in lower voltage distribution feeders). 
of all of these methods is to ensure system reliability while limiting any price differences at the "seams" between transmission and distribution that do not result from losses or congestions - that is, to maximize all welfare improving trades across the widest possible geography while respecting all physical and reliability constraints.

\subsection{Enhanced DSO models}

In enhanced DSO models, the DSO has sole responsibility for distribution level power balancing. The DSO would first aggregate all demand, DER, and aggregator bids for electricity injection or withdrawal within their network territory. The DSO would also make or aggregate any necessary forecasts of unscheduled demand or DER production (such as from solar PV). The DSO would then ensure the feasibility of these potential power flows under a range of different assumptions about potential transmission-level power flows and prices (step 1). The DSO would then provide the transmission-level BA with an aggregate demand or supply bid for energy and ancillary services that is a function of power flow and price at the transmission-distribution interface (step 2). For this process to be run in one step, this bid would need to contain price-quantity pairs at the transmission-distribution interface(s) for all potential prices and power flows that could result from the bulk system BA's subsequent economic dispatch and optimal power flow solution. The BA would then incorporate the DSO's supply-demand function into its transmission-level security-constrained economic dispatch decisions and communicate the resulting price and flows at the transmission-distribution interface to the DSO (step 3). Upon receiving BA dispatch orders, the DSO would dispatch all distribution level resources and perform any security-related re-dispatching ${ }^{7}$ to ensure that network flows in distribution are feasible and that the flow across the transmission-distribution interface is equal to the level in the BA's dispatch (step 4). Under this setup, the bulk system BA would, in theory, have and need relatively little information regarding the status or topology of the distribution system, other than the DSO supply-demand function submitted in each time period.

Some algorithms, such as those proposed by Caramanis et al. (2016), Li et al. (2014), and Huang et al. (2015)the distribution system operator (DSO clear energy and ancillary services while accounting for both transmission and distribution resources and constraints. These models "decompose" the power system into the transmission and distribution levels. ${ }^{8}$ In such methods, the distribution level problems are solved and iterated with the transmission level problem until an equilibrium solution is found. In this case, information is exchanged primarily at the transmission and distribution interface. Depending on the entity responsible for running these clearing processes (i.e. the DSO or the BA), this can be interpreted as an implementation of an enhanced DSO or enhanced BA model. Regardless, in these systems, the bulk and distribution system scheduling problems are solved independently and coordinated to reach a globally optimal (or near-optimal) solution. This bi-level structure with coordination at the transmission-distribution interface also emulates the model described by some proponents of active distribution network management (see, for example, (Saint-Pierre \& Mancarella, 2016)market constraints, and scheduled power flows at the interface with the transmis- sion system. A novel framework for ADSM, which incorporates a dual-horizon

7. As discussed in Part 1 of this two-part paper, this authority raises the importance of strict separations between the system operator role and any market participants.

8. Often this decomposition is between the meshed and radially-operated portions of the network. This has led some scholars to argue that it may be necessary to consider re-assigning the proper boundary between transmission and distribution to the meshed-radial boundary (MIT, 2016, Ch. 6). 
rolling scheduling model based on dynamic ac optimal power flow, is proposed in this paper. In the first stage (planning).

\subsection{Hybrid models}

In hybrid models, the BA and DSO share responsibility for real time power balancing. In this model, the DSO clears demand, DER, and aggregator schedules either before (Option A in Figure 1) or after (Option B in Figure 1) these schedules have been cleared with the BA. This effectively involves the DSO and BA sharing information to avoid any infeasible or conflicting dispatch orders.

Consumer, DER, and aggregator positions will depend on transmission-level outcomes and a variety of exogenous factors. Likewise, transmission-level outcomes will depend on the aggregate demand or supply at all transmission-distribution interfaces. If the DSO and BA were to execute this process in real time, the process would need to involve rapid iteration to reach a convergent solution. Alternatively, the DSO and BA could accept sub-optimal but feasible solutions. That is, the DSO and BA may accept solutions that do not maximize total system welfare but that do meet all system constraints. In such an instance, either the DSO or BA would have primacy in the case of conflicts. One mechanism for establishing primacy would be to assess the marginal value of the two conflicting dispatch options to determine which dispatch order should be executed, with the second actor then finding a feasible but potentially suboptimal alternative dispatch decision. This is likely to be more efficient, albeit more complex, than a solution in which one actor has primacy in case of all conflicts.

In systems with low penetrations of DERs and few operational measures required of the DSO, this model may be workable without substantial efficiency loss. Indeed, variations of this model are in place today and expansions of this model are proposed by CAISO et al. (2017) and ENTSO-E (2017) as intermediary solutions for the near term. In these cases, no single entity retains full responsibility for dispatch of resources in a given geography. However, with high penetrations of DERs and frequent operational measures taken by the DSO, the infrastructure and the arrangements necessary to enable such a model may increase transaction costs and prove more costly or challenging than alternatives.

\subsection{Enhanced BA models}

In enhanced bulk BA models, the DSO cedes the responsibility for ensuring the feasibility of power flows and power balancing at the distribution level to the bulk system BA. The DSO would provide the BA with all necessary information regarding the status of the distribution network (step 1). All network users - whether distribution or transmission connected - would submit bids for production or consumption to the bulk system BA directly or through an aggregator (step 2). The BA would also forecast any unscheduled generation or load (step 2). The BA would then dispatch all transmission and distribution level resources accordingly (step 3). ${ }^{9}$ This option would likely prove computationally infeasible using the algorithms currently employed by BAs to clear security-constrained economic dispatch of bulk power systems. Enhanced BA models would effectively resemble an expanded version of the market clearing and system operation models in place in the U.S. and Europe today, but with one or two orders of magnitude greater number of network branches, users, and decisions.

9. A variant of this model would have the BA issue dispatch orders to the DSO who would then execute these orders. 


\subsection{Tradeoffs and considerations}

This section describes the key tradeoffs between the above three models. We note that both the enhanced DSO and enhanced BA models require as-of-yet unproven methods for clearing and coordinating markets at a large scale. Thus, in the near term, it is likely that hybrid models with feasible but suboptimal outcomes will prevail. As DER penetration increases, regulators and policy makers may benefit from reconsidering the mechanisms that coordinate DSOs and bulk system BAs. Thus, which solution is likely to prevail?

With an efficient and low-cost method of coordinating power flows between DSOs and BAs, the enhanced DSO model is an attractive option, as it would facilitate a combined DNO/SO that retains economies of scope from network ownership and operation and would allow substantial gains from trade coordinated by a method for calculating globally-optimal (or near-optimal) distribution locational marginal prices (DLMPs). While practical application of such a coordination mechanism has not been demonstrated to date, it is possible that a method could be developed and applied in the future (see, for example, the discussion of decomposition algorithms for computing DLMPs in section 4.1).

In the near-term, lacking sophisticated and as-of-yet unproven mechanisms for coordinating power exchanges between BAs and DSOs, enhanced DSO models could significantly decrease trade between resources at the transmission level and demand and DERs at the distribution level and between DERs in one distribution system with demand in another. This could dramatically decrease the amount of welfare enhancing trades made under this construct. For context, there are over 3,000 DNO/SOs in the U.S. today. If each DSO acted as an independent balance authority within its service territory, this would increase the number of BAs operating in the U.S. by two orders of magnitude (the U.S. had 66 BAs as of July 2016) (EIA, 2017). Proponents of enhanced DSO models note that BA-DSO coordination could mimic today's inter-ISO coordination (Kristov et al., 2016). However, inter-BA trading has historically been very limited; a review of hourly U.S. trading data reveals that roughly $90 \%$ of all power produced in a given BA's territory was consumed in that territory between 1999-2012 (Cicala, 2017, p. 18). One could interpret this as meaning that balancing authorities have not historically effectively coordinated to maximize the benefits of potential trades between their areas. Alternatively, one could interpret this as the result of balancing authorities expanding their geographies to the point that maximizes the achievable gains from trade.

Neither interpretation would lead one to believe that DSOs are the optimal scope for balancing responsibility. A single distribution system is unlikely to be the ideal size to maximize gains from trade, and the enhanced DSO model would necessitate significant cross-seams trading and associated transaction costs. Furthermore, the existing evidence indicates that inter-BA coordination is sub-optimal. U.S. BAs have expanded several times in the past decade, each time realizing increased gains from trade. For example, the development of the Western Energy Imbalance Market (EIM) yielded many benefits by coordinating real time dispatch among previously independent BAs in the Western Interconnect in the U.S. (CAISO, 2017). The EIM was established in 2014, indicating that gains from trade were available but uncaptured at the time of EIM formation. Furthermore, several expansions of PJM and a recent expansion of the Midcontinent ISO in the U.S. also yielded benefits, primarily from gains from trade (Mansur \& White, 2012; MISO, 2017). In Europe, the benefits of greater market integration have been estimated to be on the order of several billion dollars per year (Newbery, Strbac, \& Viehoff, 2016). While this evidence is not definitive, it indicates that methods to coordinate markets and balancing areas are not yet fully developed, and that dramatically increasing the balkanization of markets may be very costly. 
In addition to creating a need for novel and sophisticated DSO-BA coordination mechanisms, each DSO would have to develop the computing infrastructure and knowledge required to assess the feasibility of power flows and balance power across many time scales. The cost of this infrastructure is not negligible (Greenfield \& Kwoka, 2011). The total expenses of PJM-the largest balancing authority in the U.S. by generation capacity-were roughly \$277 million in 2016 compared to total billings of over $\$ 39$ billion (roughly $0.7 \%$ of the total system costs) (PJM, 2017). Depending on the degree to which these costs scale with the size of the market (that is, whether or not they decrease substantially at the distribution level), building this infrastructure at the distribution level may or may not entail significant costs.

Enhanced bulk BA models require the BA to have a complete understanding of the DNO network and the resources and demand connected to this network. BAs have substantially greater experience than distribution utilities at efficiently and dynamically operating electricity systems, which lowers the cost of system operation (Greenfield \& Kwoka, 2011). However, accounting for all distribution system conditions and DER characteristics would require a significant increase in the complexity of BA operations, and will require new learning. For example, the CAISO system contains 26,000 miles of transmission lines, while the three largest DNOs in California together manage over 255,000 miles of distribution lines (CAISO et al., 2017). A BA-led system would require modeling the constraints of more than one order of magnitude more lines and network users. Further, it would require new computational techniques, as many distribution circuits are unbalanced 3-phase circuits and cannot be modeled using the techniques traditionally used at the transmission level (Papavasiliou, 2017). It is therefore unclear whether operating an enhanced BA model would be computationally feasible or practical with today's technology. Furthermore, there may be jurisdictional impediments to an enhanced bulk BA model in the U.S., given that distribution utilities are regulated at the state level, while ISOs/RTOs are regulated at the federal level.

In addition, enhanced bulk BA models effectively emulate independent distribution system operator (IDSO) models. In non-vertically integrated markets, the BA (serving as the distribution system operator) would be independent from the distribution network owner. A BA-led model would therefore create many of the transaction costs discussed in Part 1 of this paper series. ${ }^{10}$ These potential inefficiencies must be weighed in considering a BA-led model.

\section{Figure 1: Tradeoffs between distribution system operational models}

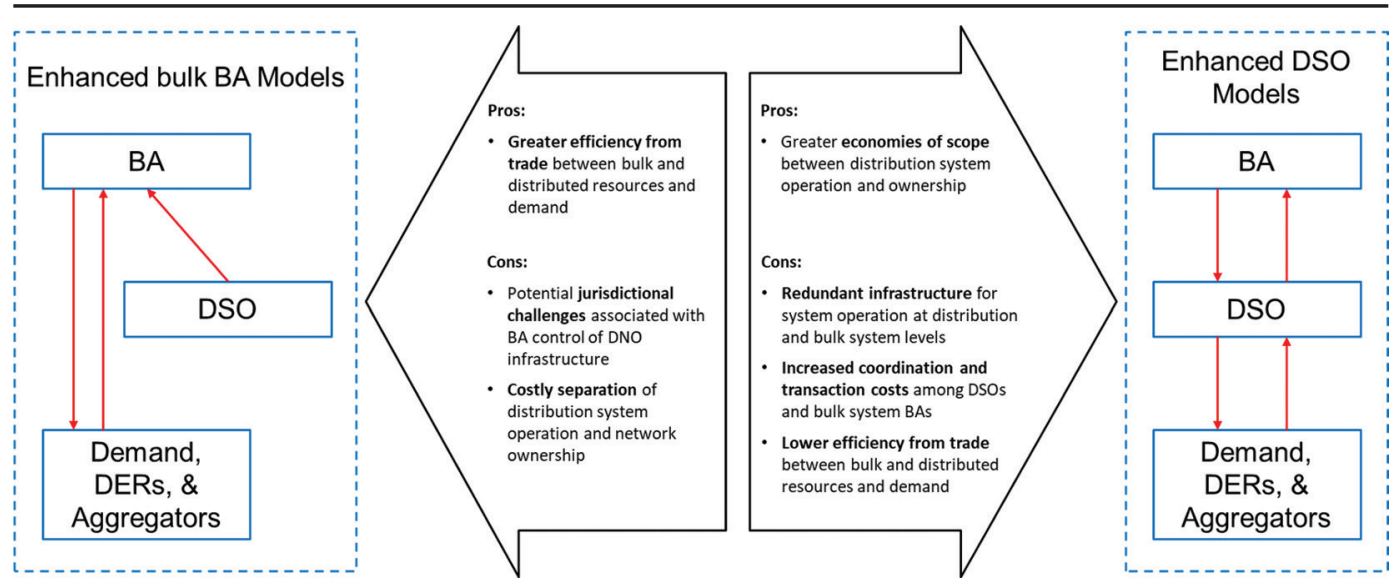

10. In Part 1, we note that, due to the frequency and nature of the interactions between the DNO and the DSO, separating distribution system operation and ownership would create substantial coordination and transaction costs. While system 
With perfect information flows and zero transaction costs between the DSO and the BA, enhanced DSO and enhanced BA models are effectively identical. In reality, of course, information flows are imperfect and not costless. Reliable methods that enable the extension of locational marginal prices into distribution networks in a manner that is computationally tractable on the time scales necessary to coordinate efficient dispatch is an active area of research (and entrepreneurial activity) (Michael Caramanis et al., 2016; Papavasiliou, 2017). Which algorithms (if any) ultimately succeed - and the information sharing, point of decomposition, and other attributes of these methods - may have implications for the responsibilities of bulk BAs and distribution network utilities. Proactively considering these implications is a useful area for further research.

This discussion highlighted the tradeoffs in establishing which entity - the DSO, the BA, or some combination of both - should be responsible for balancing power and thus computing the prices of electricity services at the distribution level. The following sections analyze what types of price signals are necessary and likely to exist at the distribution level, regardless of which entity is responsible for computing these price signals.

\section{ENERGY, ANCILLARY SERVICES, AND CAPACITY PRICES}

It is theoretically possible to extend the marginal cost-based price formation process used in bulk power systems into the distribution network to create prices for DERs and consumers reflective of network constraints and marginal costs of supply at a given time and place. In theory, globally harmonized locational marginal prices that extend through both transmission and distribution systems would be the most efficient method of coordinating dispatch and balancing at both bulk and distribution levels (Caramanis et al., 2016; Schweppe et al., 1988). Under such a system, the short run prices of energy, ancillary services, and capacity products are related to the marginal cost of providing these services. In systems with organized wholesale markets, these prices emerge from a combination of: 1) market operations that match the least cost set of generation resources with demand, 2) physical network constraints on power flows, and 3) any security-related actions taken by the system operator. In vertically integrated systems, these prices emerge from internal dispatch decisions by the vertically integrated utility. Marginal prices - in conjunction with capacity remuneration mechanisms - already serve to coordinate investment and operation decisions in generation, storage, and network resources at the bulk system level. ${ }^{11}$ While the owners of some DERs, such as homes with rooftop solar PV, do not schedule their production or consumption decisions in markets, the impacts of these resources must be accounted for in any dispatch processes.

In the near term, due to the practical difficulty of computing globally optimal distribution-level locational marginal prices at present, $\mathrm{DNO} / \mathrm{SO}$ sill need to rely on proxies for the true value of energy, ancillary services, and capacity at the distribution level. These proxies may be the price of energy at the relevant transmission node, adjusted to reflect estimated marginal losses in each distribution voltage level. In addition, as we discuss in Section 6, the price signals that the vast majority of distribution network users currently see are tariffs, which are, in the majority of cases, crude proxies for the real prices of energy and network services as well.

operators and transmission owners face similar challenges, the complexity and nature of distribution make separation more costly at the distribution level.

11. For a short summary of energy, capacity, ancillary services, and network and policy costs, we refer readers to Burger et al. (2019). 
$\mathrm{DNO} / \mathrm{SOs}$ may wish to rely on market mechanisms to identify the lowest cost resources for relieving distribution system constraints on operational timescales (this will be especially true in enhanced DSO models). The key question from a structural perspective is whether these markets should be organized by the $\mathrm{DNO} / \mathrm{SO}$ or by an independent market operator. To ensure transparency and prevent foreclosure, the market operator must maintain complete independence from market activities. This has been a key design feature of wholesale electricity and ancillary services markets in both the European and U.S. contexts. Thus, in systems with competition in the DER and/or aggregation roles and where the $\mathrm{DNO} / \mathrm{SO}$ is integrated downstream into these roles, a third-party market operator may be critical for short-term operational markets. The European market context demonstrates the possibility of independent market operators ("power exchanges") working in coordination with network owners and operators. However, such a structure can require the system operator to make out-of-market congestion management payments, which can harm efficiency (Neuhoff, Hobbs, \& Newbery, 2011). This inefficiency is related to the frequency of unexpected congestions, which, depending on the state of the distribution network, may or may not be high. This strengthens the argument for ensuring the structural independence of the $\mathrm{DNO} / \mathrm{SO}$ (see Part 1 of this two-part paper series), so that the $\mathrm{DNO} / \mathrm{SO}$ may act as a neutral market operator and integrate market activities with distribution system operations.

Some power system stakeholders have highlighted the potential for local or peer-to-peer markets to replace existing system operators and market mechanisms. These stakeholders argue that these decentralized markets will, among other things, create greater value for DER owners and enable consumers to procure power that better matches their preferences (NYDPS, 2014; Parag \& Sovacool, 2016; Rosen \& Madlener, 2016). We note two challenges that these peer-to-peer markets must overcome.

First, network externalities - losses and congestions that result from the aggregate behavior of all network uses - may make peer-to-peer architectures reliant on bilateral transactions infeasible or inefficient, as it is impossible for transactions to account for their impact on network congestions without global omniscience of all trades (Mansur \& White, 2012).

Second, power markets deliver the greatest benefits when they span the largest possible geographies. Restricting markets to specific geographies to enable peer-to-peer markets would therefore substantially reduce gains from trade, and it can also decrease market liquidity, which can increase the ability of certain participants to exercise market power and result in suboptimal market outcomes. An alternative to bilateral peer-to-peer markets is to ensure DERs are capable of participating in other more geographically diverse market mechanisms, such as existing wholesale markets, multilateral markets for distribution-level services, and/or distributed globally optimal market clearing processes.

This section focused briefly on the form of the price signals necessary for coordinating investments and operations at the distribution level. As one would expect, these price signals have direct corollaries at the transmission level. However, at the distribution level, the majority of consumers do not respond directly to market-based price signals. Rather, they respond to tariffs, the topic to which we turn next.

\section{THE ROLE OF TARIFFS}

At the distribution level, the price signals for energy, network access, and ancillary services are typically bundled in retail tariffs along with other power system costs. The vast majority of 
residential and commercial electricity consumers do not buy and sell electricity directly in markets and negotiate for network access with transmission and distribution utilities. Rather, a retailercompetitive or monopoly - assumes financial responsibility for an aggregation of customers, procuring and scheduling energy consumption and production in markets and with the relevant system operator and network owners. Network users in turn pay retailers a tariff for energy use or are paid at a tariff-determined rate for energy production. As a result, retail electricity tariffs are the primary investment and operation signals for DERs (Carley, 2009).

Given that tariffs will influence DER adoption and operation decisions in all industry structures, cost-reflective tariffs are necessary to align the incentives of network users with the incentives of the system (Ignacio J. Pérez-Arriaga et al., 2016, Chapter 4). Tariffs that do not reflect the shortrun marginal cost of energy consumption and production decisions have two deleterious effects. First, they distort investment and operation signals for DERs and electricity consumers in ways that increase total costs of delivered electricity services. Second, they shift costs between network users, as any time a user saves more on their retail bill than they reduce system costs, another system user inevitably pays for the remaining system costs. Numerous authors - for example, Kassakian et al. (2011), Borenstein (2017), Brown and Sappington (2017) - have highlighted this phenomenon in the case of rooftop solar PV, for example.

The magnitude and structure of the retail tariff may be determined by a regulatory agency, by the retailer, or both. Unfortunately, at present, these retail tariffs typically bear relatively little relation to the marginal costs of providing electricity services at any given time and location. Figure 2 below contains the number of customers in the U.S. with advanced metering infrastructure (AMI) capable of recording electricity usage profiles over time and the small fraction of these customers that actually receive a tariff that varies with time (EIA, 2017). ${ }^{12}$ Only a small fraction of all customers with AMI are presented with a "dynamic pricing" tariff that reflects the change in value of energy at different times in any capacity (Figure 2). An even smaller fraction of these customers on dynamic prices - $3 \%$ of residential customers, $40 \%$ of commercial customers, and $70 \%$ of industrial

Figure 2: Number of U.S. customers with AMI and the percent of these customers with dynamic tariffs

Number of U.S. metered sites with AMI, 2016

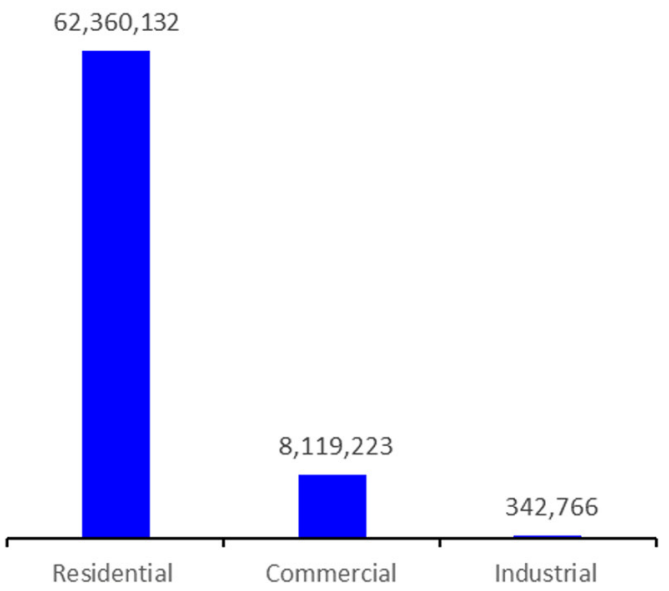

Percent of AMI enrolled in dynamic pricing, 2016

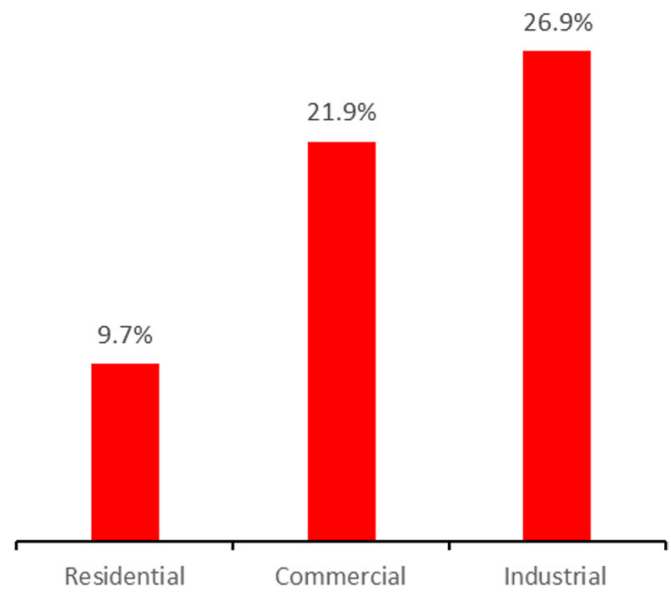

12. The Energy Information Administration's Form 861 reports the number of customers 
customers - even have the option of receiving a tariff that reflects the price of energy on an hourly basis (EIA, 2017). Other countries, such as Spain, where market-based, real-time pricing is offered as a default, have much greater experience with efficient pricing schemes.

Further, retail electricity tariffs tend to bundle the cost of energy, network and generation capacity, and policy costs and subsidies into a volumetric price that artificially inflates the marginal cost/value of energy seen by ratepayers (Fares \& King, 2017). This is highly distortionary in the cases where the vast majority of network and policy costs are residual - that is, they cannot be changed with changes in consumption or production (Woo, Lloyd-Zannetti, Orans, Horii, \& Heffner, 1995). This distortion in retail rates incentivizes customers to bypass grid-based electricity in part or in full and leads to an inefficient mix of network and generation resources. For tariffs to encourage efficient coordination between network utilities, generation companies, and myriad distributed users or producers of electricity services, it is critical that regulators design tariffs in a way that reflects marginal costs as closely as possible and does not favor private benefits over system wide welfare benefits. In practice, if regulators wish to enable customer choice and continue to allow all resources to interconnect, they must set default rates to an efficient structure (with appropriate means-tested social protections (Burger et al., 2019).

Evidence from numerous studies suggest that electricity consumers reduce consumption in response to short-term increases in electricity prices (see for example, (Allcott, 2011)despite substantial hourly variation in the wholesale market price. This paper evaluates the first program to expose residential consumers to hourly real-time pricing (RTP). Some scholars have argued that, due to transaction costs and attention limits, consumers might prefer and even respond more acutely to less-variable prices (Schneider \& Sunstein, 2017). If this is the case and consumers are charged according to a marginal-cost based tariff, competitive entities (for example, aggregators) will ultimately find value in offering contracts, hedging strategies, and demand management to help consumers reduce costs and minimize the attention they must pay to electricity prices.

Changes to industry structure at the distribution level do not fundamentally alter the importance of creating efficient, cost-reflective tariffs. A number of alternative regulatory changes could increase the use of efficient rates. Improving DNO/SO remuneration mechanisms could increase $\mathrm{DNO} / \mathrm{SO}$ incentives for enrolling customers in efficient tariff programs. In addition, improving the settlement rules for load-serving entities (LSEs) (i.e. retailers and DNO/SOs) would improve incentives for LSEs to pass on efficient price signals (Chao \& Wilson, 1987; P. Joskow \& Tirole, 2006, 2007) demonstrate how targeted curtailment of customers that have not procured sufficient capacity (directly or through a load-serving entity) helps customers internalize the value of reliability and induces efficient price response in peak price hours. In sum, ensuring LSEs are fully financially responsible for the customers they serve and enabling targeted customer curtailment would dramatically improve incentives. This would result in either LSEs passing through efficient price or creating alternative mechanisms to minimize the cost of servicing their customers.

Efficient tariffs that reflect the real-time short run marginal cost of energy delivery will help consumers or businesses identify the optimal locations for DER deployment, and the optimal operating schedules at these locations. While many regulatory authorities are considering proxies for efficient tariffs - such as time-of-use or critical peak prices that reflect average costs across different time periods - these proxies tend to contain only a fraction of the information of a truly efficient signal (Hogan, 2014). Thus, we do not discuss proxies for efficient marginal signals in much detail.

Due to customer and DNO/SO risk aversion and a variety of challenges associated with short-term electricity pricing, the DNO/SO may wish to signal valuable locations for DER investment through other means, such as through targeted procurements. We turn to this issue next. 


\section{THE ROLE OF LONG-TERM PLANNING AND FORWARD CONTRACTING FOR DISTRIBUTION NETWORK SERVICES}

The traditional network planning process involves forecasting future demand and designing the network infrastructure necessary to meet this expected demand (with a healthy operating margin). Now, however, DNO/SOs must plan their networks accounting for more flexible and dynamic load and the potential for electricity production from DERs. Cost minimizing DNO/SOs may wish to procure services from DERs and flexible demand (or aggregations thereof) as opposed to investing in network infrastructure (e.g. pursue so-called "non-wires" alternatives to traditional network or "wires" investments). However, network investment decisions are typically made months to years in advance of real time. In contrast, DER investment decisions may be made weeks to months in advance. Real-time operational decisions are made days to seconds in advance but should also be consistent with efficient long-run investment in network assets and DERs. Should the DNO/SO fail to build sufficient network capacity or contract for DER services, binding demand-driven congestions could result in undesired demand curtailment or localized blackouts. This difference in time scales creates a coordination challenge for $\mathrm{DNO} / \mathrm{SOs}$.

To address this coordination challenge, $\mathrm{DNO} / \mathrm{SO}$ and regulatory agencies are attempting to improve planning processes. Regulators have long mandated that $\mathrm{DNO} / \mathrm{SOs}$ in many states engage in integrated resource planning. In recent years, some U.S. states have begun mandating more involved and detailed planning processes, with greater emphasis on distribution system planning and more cost effective integration of DERs (see, for example, CPUC (2014) and NYDPS (2015)). These planning processes are intended to help DER developers target value-maximizing areas in $\mathrm{DNO} / \mathrm{SO}$ networks. To the extent that these plans communicate the expected marginal value of providing electricity services in any given area, they can help convey efficient coordination signals.

Once utilities have signaled expected high value areas, can they rely on efficient tariffs to provide sufficient response from DER developers, or will additional mechanisms be necessary? The answer depends on the ability of price signals to stimulate adequate investment and ensure the firmness of these investments in real time. An efficient retail tariff should include forward looking elements that signal the impact of network users' consumption or production decisions on future network investments (MIT, 2016). With efficient tariffs that fully internalized the costs (or value) of a network user's decision, the DNO/SO could, in theory, rely on the response of network users to curtail demand or production to avoid congestions or system failures. However, there are many reasons why such short-term price signals might not stimulate adequate investment on their own. These reasons have direct corollaries in the debate over the need for capacity remuneration mechanisms versus relying on "energy only" markets and short-run marginal prices to coordinate sufficient investment in firm generating capacity.

First, regulators may not allow retail tariffs to rise to the point necessary to stimulate the magnitude of network or DER investments necessary to meet high regulatory requirements for reliability. This mimics the challenge created by price caps in wholesale electricity markets that do not align with regulatory requirements for capacity adequacy (Cramton, Ockenfels, Stoft, \& others, 2013; Paul L. Joskow, 2008).

Second, there are incomplete forward markets for securing sufficient network or firm operational capacity to meet expected demand for distribution network services. DNO/SOs must make network investments in anticipation of network user behavior. However, today there are no forward mechanisms allowing consumers to express their willingness to pay for future network capacity. This problem is described well by Ofgem (2017). The absence of forward markets for network 
capacity is especially problematic given that many customers and, indeed, DNO/SOs are likely risk averse. DNO/SOs are often financially rewarded (or penalized) for meeting (or missing) reliability targets; as a result, $\mathrm{DNO} / \mathrm{SOs}$ may wish to forward contract to ensure that providers of non-wires alternatives deliver energy when needed. In addition, DER owners are likely to value long-term agreements with purchasers of the services that they provide and financial hedges against sustained periods of high prices.

Finally, energy prices alone do not signal the full value of network investments. This fact has been demonstrated repeatedly at the transmission level (I.J. Pérez-Arriaga, Rubio-Odériz, Gutiérrez, Ogando, \& Marín, 1995) and recent evidence demonstrates that this fact is likely to hold at the distribution level (MIT, 2016). In short, even if energy prices were unconstrained, consumers may still be unable to internalize the network cost impacts of their investment and operation decisions via short-run marginal prices alone.

For all of these reasons, where a $\mathrm{DNO} / \mathrm{SO}$ has determined that a non-wires investment is the most efficient solution, $\mathrm{DNO} / \mathrm{SOs}$ may wish to secure long-term contracts for capacity well in advance of real time with strict performance requirements for delivery. This practical observation is bolstered by theoretical and empirical research that predicts that transactions that navigate significant uncertainty (e.g. future demand or supply) and rely on highly specific assets with long life spans (e.g. network assets or DERs) tend towards long-term contracts (Paul L Joskow, 1985; Lafontaine \& Slade, 2007; Williamson, 1979). The most high profile non-wires alternatives programs - such as the BQDM project in New York City-have relied on such forward contracts (Coddington, Sciano, \& Fuller, 2017).

To maximize the transparency and minimize the costs of these non-wires alternatives procurements, the $\mathrm{DNO} / \mathrm{SO}$ may wish to rely on competitive procurement mechanisms. Long-term markets for firm or financial distribution network capacity rights may also aid in identifying consumer willingness to pay for network expansion and opportunities to harness elastic demand in lieu of network capacity. The contrast between markets to procure long-term contracts for non-wires alternatives and a long-term market for firm network capacity rights mirrors the distinction between participation of demand response providers in wholesale electricity or capacity markets versus full participation of demand in these markets. In either case, the exact design of these forward markets for non-wires alternatives or firm network capacity is a subject ripe for further research. The existing body of literature on transmission network investments and generation adequacy provides a strong theoretical starting point.

In order to prevent foreclosure, the operator of these forward markets should be fully independent from any market participants. This implies that in systems in which the DNO/SO is not fully unbundled from DER ownership or aggregation (retail or otherwise), a third-party market operator may be necessary to create a level playing field between monopoly and non-monopoly providers. Alternatively, the DNO/SO could manage the procurement process subject to closely monitored open standards, data transparency requirements, and third-party review of the bids. Open procurement mechanisms could mirror those leveraged by some vertically integrated utilities today. For example, to ensure transparency, Pacific Gas and Electric (PG\&E) in California uses a third party to solicit bids for non-wire alternatives to distribution network infrastructure and an "independent evaluator" to review these bids (PG\&E, 2017). Similar processes are used by vertically integrated utilities to consider procurement of generation from independent power producers versus building and owning their own generation assets. As replacing network infrastructure with non-wires alternatives becomes more commonplace, the $\mathrm{DNO} / \mathrm{SO}$ may wish to run many auctions per year. Communicating auction requirements to a third-party operator or engaging in thorough regulatory oversight 
will likely increase transaction costs significantly. In this case, it may become advantageous to address concerns about potential anti-competitive practices through structural reforms - that is, by barring DNO/SOs from participating in DER ownership and aggregation as discussed in Part 1 of this paper series.

\section{DISCUSSION AND CONCLUSIONS}

If integrated efficiently, the emergence of DERs provides new opportunities to lower power system costs. However, the mechanisms developed to coordinate investment and operation in electric power systems were not developed with significant participation from distribution-connected resources in mind. The power system is likely to become increasingly decentralized and vertically disaggregated as participation from DERs and demand-side resources increases. This necessitates a renewed focus on the mechanisms that coordinate vertically and horizontally disaggregated actors in the power sector. We provide three key conclusions regarding coordination and price signals at the distribution level.

First, as the penetration of DERs increases and as DNO/SOs increasingly rely on DERs as alternatives to traditional network infrastructure, power system stability and reliability will be increasingly tied to how distribution-connected resources are dispatched. However, today, no single entity has visibility over distribution network constraints and capability to efficiently modify dispatch according to these constraints. This requires a reconsideration of the entity that is responsible for balancing power on operational timescales and mechanisms for coordination between distribution system and bulk power system balancing. Two likely potential models emerge: one in which the DSO takes full responsibility for distribution-level balancing, and one in which the bulk system balancing authority takes responsibility. Both models have tradeoffs and their most efficient implementation depends on as-yet-unproven methods for computing a globally optimal dispatch and power flow solution that spans transmission and distribution networks alike. An enhanced DSO system will require efficient coordination mechanisms between the DSO and the bulk system balancing authority. Without such coordination mechanisms, a DSO-led system could significantly balkanize electricity markets and reduce welfare improving trade. A bulk system balancing authority-led system would eliminate significant economies of scope between the system operator and the DNO. However, given that the BA-led system would enable balancing and coordination over the widest possible geographic area, such a system would likely maximize the possible gains from trade. The costs and benefits of different options for power balancing at the distribution level is a key area for further research. In the short term, suboptimal but feasible arrangements involving increased communication between DSOs and BAs and shared responsibility will likely prevail.

Second, price signals at the distribution level — retail tariffs in particular — must be dramatically improved to better reflect the marginal cost of consuming or producing a given service at a given time and location in distribution networks. This requires a rethinking of the purpose of retail tariffs. Tariffs are no longer simply a mechanism for cost recovery within social and regulatory constraints. The emergence of DERs dramatically expands the potential number of owners and operators of electricity resources. As a result, tariffs must serve the purpose of supporting the coordination of efficient investments and operations of the power system's diverse set of resources.

Finally, in addition to improving retail tariffs, competitive forward procurements for DERs and flexible demand as alternatives to network assets will likely increase efficiency in all market structures (that is, structures with and without competition for generation and aggregation). These procurements will likely mimic generation forward capacity procurements increasingly common at 
the wholesale level. Should the $\mathrm{DNO} / \mathrm{SO}$ not be, at a minimum, legally unbundled from aggregator or DER-owning/operating affiliates, third-party monitoring or operation of these competitive procurements may create a more competitive environment and increase transparency and efficiency of the auctions. Similarly, in vertically integrated power systems, standardized, open solicitations or third-party run solicitations may be required if an incentive regulation scheme is not in place.

\section{ACKNOWLEDGMENTS}

The authors would like to thank Professor Richard Schmalensee, Professor Paul Joskow, Professor William Hogan, and Ian Schneider for their thoughtful comments and edits to this paper. This paper presents the views and positions of the authors who are solely responsible for its content, including any errors.

\section{REFERENCES}

Allcott, H. (2011). "Rethinking real-time electricity pricing.” Resource and Energy Economics 33(4): 820-842. https://doi. org/10.1016/j.reseneeco.2011.06.003.

Bahramirad, S., A. Khodaei, and R. Masiello (2016). "Distribution Markets.” IEEE Power \& Energy Magazine, $102-106$. https://doi.org/10.1109/MPE.2016.2543121.

Baldick, R. and E. Kahn (1993). "Network costs and the regulation of wholesale competition in electric power." Journal of Regulatory Economics 5(4): 367-384. https://doi.org/10.1007/BF01065403.

Bollinger, B. and K. Gillingham (2012). "Peer Effects in the Diffusion of Solar Photovoltaic Panels." Marketing Science (July 2015). https://doi.org/10.1287/mksc.1120.0727.

Borenstein, S. (2017). "Private Net Benefits of Residential Solar PV: The Role of Electricity Tariffs, Tax Incentives, and Rebates." Journal of the Association of Environmental and Resource Economists 4(S1): S85-S122. https://doi. org/10.1086/691978.

Borenstein, S. and J. Bushnell (2015). "The U.S. electricity industry after 20 years of restructuring." Annual Review of Economics. https://doi.org/10.1146/annurev-economics-080614-115630.

Brown, D.P. and D.E.M. Sappington (2017). "Designing compensation for distributed solar generation: Is net metering ever optimal?” The Energy Journal 38(3): 1-32. https://doi.org/10.5547/01956574.38.3.dbro.

Burger, S.P., I. Schneider, A. Botterud, and I.J. Pérez-Arriaga (2019). "Fair, equitable, and efficient tariffs in the presence of distributed energy resources." In Consumers, Prosumers, Prosumagers: How service innovations will disrupt utility business model, F.P. Sioshansi (Ed.). Academic Press.

CAISO (2017). Western EIM Benefits Report: Third Quarter 2017. Folsom, CA. Retrieved from https://www.westerneim. com/Documents/ISO-EIMBenefitsReportQ3_2017.pdf.

CAISO, PG\&E, SCE, SDG\&E, \& More Than Smart (2017). Coordination of Transmission and Distribution Operations in a High Distributed Energy Resource Electric Grid. Folsom, CA. Retrieved from https://www.caiso.com/Documents/ MoreThanSmartReport-CoordinatingTransmission_DistributionGridOperations.pdf.

Caramanis, M., E. Ntakou, W.W. Hogan, A. Chakrabortty, and J. Schoene (2016). "Co-Optimization of Power and Reserves in Dynamic T\&D Power Markets With Nondispatchable Renewable Generation and Distributed Energy Resources.” Proceedings of the IEEE 104(4): 807-836. https://doi.org/10.1109/JPROC.2016.2520758.

Carley, S. (2009). "Distributed generation: An empirical analysis of primary motivators." Energy Policy 37(5): 1648-1659. https://doi.org/https://doi.org/10.1016/j.enpol.2009.01.003.

Chao, H.-P. and R. Wilson (1987). “Priority Service: Pricing, Investment, and Market Organization.” The American Economic Review 77(5): 899-916. Retrieved from http://www.jstor.org/stable/1810216.

Cicala, S. (2017). Imperfect Markets versus Imperfect Regulation in U.S. Electricity Generation. Chicago, IL. Retrieved from http://home.uchicago.edu/ scicala/papers/elec_gov_v_mkt_draft_2.pdf. https://doi.org/10.3386/w23053.

Coddington, M., D. Sciano, and J. Fuller (2017). “Change in Brooklyn and Queens: How New York's Reforming the Energy Vision Program and Con Edison Are Reshaping Electric Distribution Planning." IEEE Power and Energy Magazine 15(2): 40-47. https://doi.org/10.1109/MPE.2016.2639179. 
Cohen, M.A., P.A. Kauzmann, and D.S. Callaway (2015). Economic Effects of Distributed PV Generation on California's Distribution System (EI @ Haas WP No. 620). Berkeley, CA. Retrieved from http://ei.haas.berkeley.edu/research/papers/ WP260.pdf.

Corneli, S., S. Kihm, and L. Schwartz (2015). Electric Industry Structure and Regulatory Responses in a High Distributed Energy Resources Future (Future Electric Utility Regulation No. LBNL-1003823). Berkeley, CA.

CPUC (2014). Order Instituting Rulemaking Regarding Policies, Procedures and Rules for Development of Distribution Resources Plans Pursuant to Public Utilities Code Section 769. San Francisco, CA.

Cramton, P., A. Ockenfels, S. Stoft, et al. (2013). "Capacity market fundamentals." Economics of Energy \& Environmental Policy 2(2): 27-46. https://doi.org/10.5547/2160-5890.2.2.2.

Darghouth, N.R., G. Barbose, and R. Wiser (2011). "The impact of rate design and net metering on the bill savings from distributed PV for residential customers in California.” Energy Policy 39(9): 5243-5253. https://doi.org/10.1016/j.enpol.2011.05.040.

DOE DSPx (2017). Modern Distribution Grid Report Volume I: Customer and State Policy Driven Functionality. Washington, D.C.

EIA (2017). Form EIA-861. Washington, D.C.

Eid, C., P. Codani, Y. Perez, J. Reneses, and R. Hakvoort (2016). "Managing electric flexibility from Distributed Energy Resources: A review of incentives for market design.” Renewable and Sustainable Energy Reviews 64: 237-247. https://doi. org/10.1016/j.rser.2016.06.008.

ENTSO-E (2017). Distributed Flexibility and the Value of TSO/DSO Coordination. Brussels, Belgium. Retrieved from https://www.entsoe.eu/Documents/Publications/Position papers and reports/entsoe_pp_DF_1712_web.pdf?Web=1.

European Commission (2009). Directive 2009/72/EC Concerning Common Rules for the Internal Market in Electricity and Repealing Directive 2003/54/EC. Brussels, Belgium.

Fares, R.L. and C.W. King (2017). "Trends in transmission, distribution, and administration costs for U.S. investor-owned electric utilities.” Energy Policy 105: 354-362. https://doi.org/10.1016/j.enpol.2017.02.036.

Fares, R.L. and M.E. Webber (2017). "The impacts of storing solar energy in the home to reduce reliance on the utility." $N a$ ture Energy 2: 17001. Retrieved from http://dx.doi.org/10.1038/nenergy.2017.1.

FERC (1999). Order No. 2000, Final Rule. Regulation Transmission Organizations (Docket No. RM99-20-000). Washington, D.C.

Firestone, R., C. Marnay, and K.M. Maribu (2006). "The Value of Distributed Generation under Different Tariff Structures." In ACEEE Summer Study on Energy Efficiency in Buildings. ACEEE.

Gilbraith, N. and S.E. Powers (2013). "Residential demand response reduces air pollutant emissions on peak electricity demand days in New York City.” Energy Policy 59: 459-469. https://doi.org/10.1016/j.enpol.2013.03.056.

Greenfield, D. and J. Kwoka (2011). “The cost structure of regional transmission organizations.” The Energy Journal 32(4): 159-181. https://doi.org/10.5547/ISSN0195-6574-EJ-Vol32-No4-8.

Hledik, R. and G. Greenstein (2016). “The distributional impacts of residential demand charges.” Electricity Journal 29(6): 33-41. https://doi.org/10.1016/j.tej.2016.07.002.

Hogan, W.W. (2013). "Electricity Scarcity Pricing Through Operating Reserves.” Economics of Energy \& Environmental Policy 2(2): 1-27. https://doi.org/10.5547/2160-5890.2.2.4.

Hogan, W.W. (2014). Time of Use Rates and Real-Time Prices. Cambridge, MA. Retrieved from http://www.hks.harvard.edu/ fs/whogan/Hogan_TOU_RTP_Newark_082314.pdf.

Huang, S., Q. Wu, S.S. Oren, R. Li, and Z. Liu (2015). "Distribution Locational Marginal Pricing Through Quadratic Programming for Congestion Management in Distribution Networks." IEEE Transactions on Power Systems 30(4): 2170 2178. https://doi.org/10.1109/TPWRS.2014.2359977.

Joskow, P.L. (1985). "Vertical Integration and Long-Term Contracts: The Case of Coal-Burning Electric Generating Plants." Journal of Law, Economics, \& Organization 1(1): 33-80. Retrieved from http://www.jstor.org/stable/764906.

Joskow, P.L. (1996). "Introducing Competition into Regulated Network Industries: from Hierarchies to Markets in Electricity." Industrial and Corporate Change 5(October): 341-382. https://doi.org/10.1093/icc/5.2.341.

Joskow, P.L. (2008). "Capacity payments in imperfect electricity markets: Need and design.” Utilities Policy 16(3): 159-170. https://doi.org/10.1016/j.jup.2007.10.003.

Joskow, P.L. and J. Tirole (2006). "Retail electricity competition.” The RAND Journal of Economics 37(4): 799-815. https:// doi.org/10.1111/j.1756-2171.2006.tb00058.x.

Joskow, P.L. and J. Tirole (2007). "Reliability and competitive electricity markets." The RAND Journal of Economics 38(1): 60-84.

Kassakian, J., R. Schmalensee, G. Desgroseilliers, T. Heidel, K. Afridi, A. Farid, ... G. Wilson (2011). The Future of the Electric Grid. Cambridge, MA: Massachusetts Institute of Technology.

All rights reserved. Copyright (C) 2019 by the IAEE. 
Kind, P. (2013). Disruptive Challenges: Financial Implications and Strategic Responses to a Changing Retail Electric Business. Washington, D.C.

Kristov, L., P. De Martini and J.D. Taft (2016). “A Tale of Two Visions: Designing a Decentralized Transactive Electric System.” IEEE Power and Energy Magazine 14(3): 63-69. https://doi.org/10.1109/MPE.2016.2524964.

Lafontaine, F. and M. Slade (2007). "Vertical Integration and Firm Boundaries: The Evidence." Journal of Economic Literature 45(3): 629-685. Retrieved from http://www.aeaweb.org/articles?id=10.1257/jel.45.3.629.

Li, R. and Q. Wu (2014). "Distribution LocationalMarginal Pricing for Optimal Electric Vehicle Charging Management." IEEE Transactions on Power Systems 29(4): 1866. https://doi.org/10.1109/TPWRS.2014.2325414.

Mansur, E.T. and M.W. White (2012). Market Organization and Efficiency in Electricity Markets. Hanover, NH. Retrieved from https://www.dartmouth.edu/ mansur/papers/mansur_white_pjmaep.pdf.

Martini, P. De, L. Kristov, and L. Schwartz (2015). Distribution Systems in a High Distributed Energy Resources Future: Planning, Market Design, Operation and Oversight (Future Electric Utility Regulation No. 2). Berkeley, CA.

Mathieu, J.L., M. Dyson, and D.S. Callaway (2012). "Using Residential Electric Loads for Fast Demand Response: The Potential Resource and Revenues, the Costs, and Policy Recommendations." In Proceedings of the ACEEE Summer Study on Buildings (pp. 189-203). Pacific Grove, CA: ACEEE.

MISO (2017). Value Proposition Study Reveals Billions in Benefits for 2016. Retrieved from http://www.misomatters. org/2017/02/value-proposition-study-reveals-billions-in-benefits-for-2016/.

Neubauer, J. and M. Simpson (2015). Deployment of Behind-the-Meter Energy Storage for Demand Charge Reduction. Golden, CO. https://doi.org/10.2172/1168774.

Neuhoff, K., B.F. Hobbs, and D. Newbery (2011). Congestion Management in European Power Networks: Criteria to Assess the Available Options (DIW Berlin Discussion Paper No. 1161). Berlin, Germany.

Newbery, D., G. Strbac, and I. Viehoff (2016). "The benefits of integrating European electricity markets.” Energy Policy 94: 253-263. https://doi.org/https://doi.org/10.1016/j.enpol.2016.03.047.

NYDPS (2014). Case 14-M-0101 Proceeding on Motion of the Commission in Regard to Reforming the Energy Vision: DPS Staff Report and Proposal. Albany, NY.

NYDPS (2015). Case 14-M-0101-Proceeding on Motion of the Commission in Regard to Reforming the Energy Vision: Distributed System Implementation Plan Guidance. Albany, NY.

Ofgem (2017). Reform of electricity network access and forward-looking charges: a working paper. London, UK.

Papavasiliou, A. (2017). “Analysis of Distribution Locational Marginal Prices.” IEEE Transactions on Smart Grid 3053(c): 1-1. https://doi.org/10.1109/TSG.2017.2673860.

Parag, Y. and B.K. Sovacool (2016). "Electricity market design for the prosumer era.” Nature Energy 1: 16032. Retrieved from http://dx.doi.org/10.1038/nenergy.2016.32.

Pérez-Arriaga, I.J., C. Knittel, A. Bharatkumar, M. Birk, S.P. Burger, J.P. Chaves-Ávila, ... N. Xu (2016). Utility of the Future: An MIT Energy Initiative response to an industry in transition. Cambridge, MA: Massachusetts Institute of Technology. Retrieved from http://energy.mit.edu/research/utility-future-study/.

Pérez-Arriaga, I.J., F. Rubio-Odériz, J.F.P. Gutiérrez, J.A. Ogando, and J. Marín (1995). "Marginal pricing of transmission services: An analysis of cost recovery." IEEE Transactions on Power Systems 10(1): 65-72. https://doi.org/10.1109/59.373981.

PG\&E (2017). Distribution Resources Plan Request for Offers: Demo C-El Nido Substation Solicitation Protocol. San Francisco, CA. Retrieved from https:/www.pge.com/pge_global/common/pdfs/for-our-business-partners/energy-supply/ electric-rfo/wholesale-electric-power-procurement/2017-distributed-resources-planning-and-request-for-offers/DRP Demo_C_Protocol_2017_Final.pdf.

PJM (2017). (R)evolutionary Thinking: PJM 2016 Annual Report. Norristown, PA.

Rosen, C. and R. Madlener (2016). "Regulatory options for local reserve energy markets: Implications for prosumers, utilities, and other stakeholders.” The Energy Journal 37(SI2): 39-50. https://doi.org/10.5547/01956574.37.SI2.cros.

Rubio-Oderiz, F.J. and I.J. Pérez-Arriaga (2000). "Marginal pricing of transmission services: a comparative analysis of network cost allocation methods.” IEEE Transactions on Power Systems 15(1): 448-454. https://doi.org/10.1109/59.852158.

Ruester, S., S. Schwenen, C. Batlle, and I.J. Pérez-Arriaga (2014). "From distribution networks to smart distribution systems: Rethinking the regulation of European electricity DSOs.” Utilities Policy 31(Supplement C): 229-237. https://doi.org/ https://doi.org/10.1016/j.jup.2014.03.007.

Saint-Pierre, A. and P. Mancarella (2016). "Active Distribution System Management : A Dual-Horizon Scheduling Framework for DSO / TSO Interface Under Uncertainty.” IEEE Transactions on Smart Grid 8(5): 1-12. https://doi.org/10.1109/ TSG.2016.2518084.

Schmalensee, R., I.J. Pérez-Arriaga, V. Bulovic, R. Armstrong, C. Batlle, P. Brown, ... C. Vergara (2015). The Future of Solar Energy. Cambridge, MA. 
Schneider, I. and C.R. Sunstein (2017). "Behavioral considerations for effective time-varying electricity prices." Behavioural Public Policy 1(2): 219-251. https://doi.org/10.1017/bpp.2017.2.

Schweppe, F.C., M.C. Caramanis, R.D. Tabors, and R.E. Bohn (1988). Spot pricing of electricity. Boston, mA: Kluwer Academic Publishers. https://doi.org/10.1007/978-1-4613-1683-1.

Sioshansi, R. (2016). "Retail electricity tariff and mechanism design to incentivize distributed renewable generation." Energy Policy 1-11. https://doi.org/10.1016/j.enpol.2015.12.041.

Taft, J. and A. Becker-Dippmann (2015). Grid Architecture. Richland, WA. Retrieved from https://energy.gov/sites/prod/ files/2015/04/f22/QER Analysis_Grid Architecture_0.pdf. https://doi.org/10.2172/1176825.

Williamson, O.E. (1979). "Transaction-cost economics: the governance of contractual relations." The Journal of Law and Economics 22(2): 233-261. https://doi.org/10.1086/466942.

Woo, C.-K., D. Lloyd-Zannetti, R. Orans, B. Horii, and G. Heffner (1995). "Marginal Capacity Costs of Electricity Distribution and Demand for Distributed Generation.” The Energy Journal 16(2): 111-130. https://doi.org/10.5547/ISSN01956574-EJ-Vol16-No2-6. 